\title{
Older Clients with Questionable Legal Competence: Elder Law Practitioners and Treating Physicians
}

Marshall B. Kapp

Follow this and additional works at: http://open.mitchellhamline.edu/wmlr

\section{Recommended Citation}

Kapp, Marshall B. (2010) "Older Clients with Questionable Legal Competence: Elder Law Practitioners and Treating Physicians," William Mitchell Law Review: Vol. 37: Iss. 1, Article 10.

Available at: http://open.mitchellhamline.edu/wmlr/vol37/iss1/10 


\title{
OLDER CLIENTS WITH QUESTIONABLE LEGAL COMPETENCE: ELDER LAW PRACTITIONERS AND TREATING PHYSICIANS
}

\author{
Marshall B. Kapp ${ }^{\dagger}$

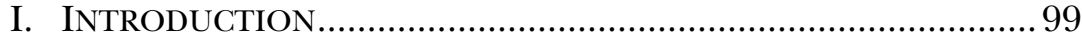 \\ II. EXPLANATIONS FOR THE INTERPROFESSIONAL TENSION....... 103 \\ III. ADDRESSING THE INTERPROFESSIONAL TENSION ................... 111

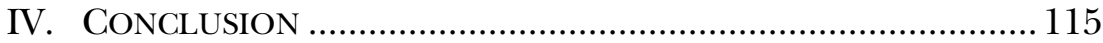

\section{INTRODUCTION}

Issues arise with some frequency in elder law practice, ${ }^{1}$ as well as in legal practices wherein attorneys counsel parties who interact-or who contemplate interacting-with older persons, concerning the cognitive and emotional ability of an older individual to make legally significant decisions. Questions about a person's legal competence and clinical capacity ${ }^{2}$ may arise

$\dagger$ Director, Florida State University Center for Innovative Collaboration in Medicine \& Law; Professor, Department of Geriatrics and Courtesy Professor in College of Law; Affiliate, Florida State University Claude Pepper Institute. Professor Emeritus, Wright State University School of Medicine. B.A., Johns Hopkins University; J.D. (With Honors) George Washington University; M.P.H., Harvard University. A version of this essay was presented at the 2010 Annual Conference of the Southeastern Association of Law Schools (SEALS) in Palm Beach, Florida.

1. For background information on the emerging professional field of elder law, see generally National Association of Elder Law Attorneys, www.naela.org (last visited Sept. 7, 2010) and the other essays in this publication.

2. The terms "competence" and "capacity" frequently are used interchangeably in common parlance. However, the two terms technically refer to distinct concepts. Jason Karlawish, Measuring Decision-Making Capacity in Cognitively Impaired Individuals, 16 Neurosignals 91, 92 (2008). As used in this essay, "competence" refers to a formal adjudication by a court or other authorized judicial or administrative body regarding the legal authority of an individual to make decisions with legal consequences. By contrast, "capacity" refers to a clinical, extralegal working impression concerning a person's ability to engage in a rational decision-making process. "A capacity assessment is a clinical assessment." Id.; see also Am. BAR Ass'N COMm'N ON LAW \& Aging \& AM. PSYChOlOGical Ass'N, 
regarding decision-making in both dramatic and everyday ${ }^{3}$ factual contexts, most importantly medical treatment choices, ${ }^{4}$ personal decisions such as where and with whom to reside, financial transactions, ${ }^{5}$ and execution of a will or other estate planning instrument.

The physicians who have treated the person whose competence is being called into question (the "allegedly incompetent person") and/or the medical records generated by those treating physicians ${ }^{6}$ often are sought by attorneys as sources of evidence regarding the physicians' first-hand observations of the patient's symptoms and behaviors, the clinical diagnoses made by the physicians, and the treatments offered and dispensed to the patient. ${ }^{7}$ The major medical conditions potentially complicating a patient's mental competence-namely, dementia, depression, ${ }^{9}$

AsSESSMENT OF Older Adults With Diminished CAPACITY: A HANDBOOK FOR LAWYERS, 1-9 (2005) [hereinafter ABA-APA] (discussing generally the issues surrounding decreased capacity).

3. See James M. Lai \& Jason Karlawish, Assessing the Capacity to Make Everyday Decisions: A Guide for Clinicians and an Agenda for Future Research, 15 AM. J. GERIATRIC PSYCHIATRY 101, 105 (2007) (discussing research regarding approaches to assessing everyday decision-making capacity).

4. See, e.g., Miriam B. Rodin \& Supriya Gupta Mohile, Assessing Decisional Capacity in the Elderly, 35 SEMINARS IN ONCOLOGY 625, 625 (2008) (discussing capacity assessment in the context of medical treatment decisions).

5. See Daniel C. Marson et al., Clinical Interview Assessment of Financial Capacity in Older Adults with Mild Cognitive Impairment and Alzheimer's Disease, $57 \mathrm{~J}$. AM. GERIATRICS SOC'Y 806, 807 (2009) (stating that the financial capacity of older adults is a growing concern).

6. See generally S. Sandy Sanbar, Medical Records: Paper and Electronic, in LEGAL MEDICINE 347-56 (7th ed. 2007) (discussing that medical records are documentation of what happened to the patient and are valuable in litigation).

7. But see Joel S. Newman, A Ten-Year Survey of Incompetency Hearings in Forsyth County, North Carolina (Wake Forst Univ. Legal Studies Paper No. 1661084), available at http:/ / papers.ssrn.com/sol3/papers.cfm?abstract_id=1661084 (finding that in fifty-one percent of the almost four hundred incompetency hearings in Forsyth County, North Carolina from 1998 to 2007, there was no input from a medical or psychological professional, nor were there medical records in the public files).

8. See generally Cynthia M. Carlsson et al., Dementia Including Alzheimer's Disease, in HAZzard's Geriatric MEdicine \& Gerontology 797, 811 (Jeffrey B. Halter et al. eds., 6th ed. 2009) (explaining Alzheimer's disease is the leading cause of dementia, both of which are associated with age); Richard H. Fortinsky et al., Primary Care Physicians' Dementia Care Practices: Evidence of Geographic Variation, 50 Gerontologist 179, 179 (2010) ("Dementia is a health problem of growing importance for primary care physicians . . . who see older patients in ambulatory care settings.”); AlzHEIMER's DiSEASE INT'L, WORLD AlzHEIMER REPORT 2009 (2009), http://www.alz.co.uk/research/files/WorldAlzheimerReport.pdf (discussing the prevalence, impact, and nature of dementia). For a comparative legal perspective, 
delirium $^{10}$ (the "three D's"), and various psychoses ${ }^{11}$ - typically are seen and treated by the older person's primary care physician.

In addition to the fact-provider role, the treating physician also may be solicited to provide an expert opinion, based upon that physician's direct experience with the allegedly incompetent person, regarding that person's present or previous ${ }^{12}$ ability to make decisions, for purposes of having that opinion admitted and considered within a legal setting. ${ }^{13}$ Further, an attorney may seek a treating physician's records as a partial basis for the formulation of an expert opinion about the competence of the alleged incompetent person when the expert opinion is to be rendered by a non-treating physician employed by the attorney for forensic purposes. ${ }^{14}$

see Sjef Gevers, Dementia and the Law, 13 Eur. J. Health L. 209, 211-16 (2006) (examining a variety of important issues related to dementia including "the availability of provision of care" and "treatment and non treatment decisions.").

9. See generally Dan G. Blazer, Late-Life Mood Disorders, in HAZZARD's GERIATRIC Medicine \& Gerontology, supra note 8, at 849 (detailing how, among mood disorders, depression is the most frequent cause of emotional disturbance among older adults).

10. See generally Katherine B. Auerswald et al., The Informed Consent Process in Older Patients Who Developed Delirium: A Clinical Epidemiologic Study, 110 Am. J. Med. 410 (1997) (noting that delirium "poses unique ethical challenges to the informed consent process" and highlighting these issues by examining the use and non-use of competency and cognitive assessments on elderly patients undergoing medical and surgical procedures).

11. See generally Danielle L. Anderson \& Peter V. Rabins, Schizophrenia, in HAZZARD's GERIATRIC MEDiCINe \& GERONTOlOGY, supra note 8, at 859 (discussing schizophrenia's association with delirium, and its onset after the age of forty).

12. Retrospective inquiry into a person's earlier mental state often takes place in the context of a will contest challenging a testator's testamentary capacity. See generally Thomas G. Gutheil, Common Pitfalls in the Evaluation of Testamentary Capacity, 35 J. AM. ACAD. Psychiatry \& L. 514 (2007) (highlighting some of the differences between testamentary capacity determinations and other forensic assessments and discussing common challenges associated with testamentary capacity evaluations); see Kenneth I. Shulman et al., Assessment of Testamentary Capacity and Vulnerability to Undue Influence, 164 AM. J. PsYCHIATRY 722, 722 (2007) (noting that "the high prevalence of cognitive impairment and dementia in older adults creates a fertile environment for challenges to wills").

13. Regarding the role of expert opinion evidence, see generally 2 AM. JUR. Trials $\$ 585$ (2009) (offering guidance with regard to issues such as the use, selection, and compensation of expert witnesses).

14. The term "forensic" refers to the application of scientific (including medical) expertise, through the preparation of reports, to help resolve legal issues. See Black's Law Dictionary 676 (8th ed. 2004) (defining "forensic" as "used in or suitable to courts of law or public debate"). 
Attorneys' retention of expert consultants ${ }^{15}$ specifically for forensic evaluations (that is, specifically to generate expert opinion testimony for presentation to the court or other legal forum) raises a panoply of challenges for legal practitioners ${ }^{16}$ and the courts, ${ }^{17} \mathrm{a}$ comprehensive discussion of which would go beyond the scope of the present essay. Rather, this essay concentrates on the professional relationship present between the elder law attorney who is involved in a situation in which the decision-making competence of an older person is questioned, on one side, and the treating physician of the same older person, on the other.

Competence is a "socio-legal construct"" and, within the boundaries of that construct, a competence determination involves the "intersection of legal doctrine, behavioral science research, and clinical practice." ${ }^{19}$ The attorney-physician interaction in this arena frequently is less than ideal. ${ }^{20}$ This essay examines some of the

15. Psychologists as well as psychiatrists and other physicians are frequently hired by attorneys to perform the expert evaluator function. See, e.g., CHANGES IN DECISION-MAKING CAPACITY IN Older Adults: ASSESSMENT AND INTERVENTION 110 (Sara Hone Qualls \& Michael A. Smyer eds., 2007). The pool of good potential expert witnesses is limited. See ABA-APA, supra note 2, at 32 ("In major metropolitan areas lawyers are more likely to be able to identify internists, psychiatrists, and psychologists with relevant background. The reality is, however, that the number of professionals with ideal credentials is small."); Kathryn Kaye \& Michael Kenny, The Business of Geropsychology: Billing and Preparing Legal Reports and Testimony, in Changes in Decision-Making CAPACITY IN Older AdUlts: Assessment AND INTERVENTION, supra, at 299 ("Forensic evaluation [of decision-making capacity] is not for the faint of heart, nor is it a suitable choice for individuals who have an aversion to detail or a low tolerance for ambiguity.").

16. See generally Adam F. Streisand \& James E. Spar, A Lawyer's Guide to Diminishing Capacity and Effective Use of Medical Experts in Contemporaneous and Retrospective Evaluations, 33 Am. C. TRuST \& EsT. Couns. J. 180 (2007) (seeking to provide attorneys with information to "demystify medical records" and explaining "clinical features and diagnosis of common mental disorders and syndromes known to affect capacity" in a manner that is "accessible" to attorneys).

17. See Kenneth C. Dudley \& R. Turner Goins, Guardianship Capacity Evaluations of Older Adults: Comparing Current Practice to Legal Standards in Two States, 15 J. AGING \& SOC. POL'Y 97, 109 (2003) (discussing state courts' differences in the types of tests used to determine capacity).

18. Andrea M. Newberry \& Arlin K. Pachet, An Innovative Framework for Psychosocial Assessment in Complex Mental Capacity Evaluations, 13 Psychol., Health \& MED. 438, 439 (2008); see also Israel Doron, Elder Guardianship Kaleidoscope - A Comparative Perspective, 16 INT'L J. L. POL'Y \& FAM. 368, 370 (2002) (providing general background of countries' socio-legal systems in the context of aging societies).

19. Michael A. Smyer, Aging and Decision-Making Capacity: An Overview, in Changes in Decision-Making CAPACITY IN Older Adults: Assessment AND INTERVENTION, supra note 15 , at 3, 5 .

20. See Jennifer Moye et al., Clinical Evidence in Guardianship of Older Adults is 
reasons for such interprofessional friction and makes a few suggestions for productively addressing the tension in a manner likely to benefit the allegedly incompetent person.

Before proceeding with that discussion, however, an important caveat is in order. This essay does not at all purport to present the results of a rigorous scientific study, either quantitative or qualitative. ${ }^{21} \quad$ Rather, this essay offers the author's own reflections and impressions formulated on the basis of his particular professional experience as an academic attorney who has worked for many years in medical educational environments, supplemented by his individual conversations with a small convenience sample of experienced physicians conducted for purposes of this project. ${ }^{22}$ The explanations and suggestions that follow should be understood and evaluated with this caveat in mind.

\section{EXPLANATIONS FOR THE INTERPROFESSIONAL TENSION}

There is an array of plausible explanations for the frequent tension that develops between elder law attorneys and treating physicians in the sphere of decision-making competence determinations. Perhaps most fundamental is the fact that attorneys involved in cases raising questions about decision-making competence identify the pertinent issues and objectives in a very different way than do the treating physicians of an alleged incompetent person:

Both [physician-patient and attorney-client] relationships require professionalism, ethical conduct, extensive skill and training, and confidentiality, yet they are practiced in diametrically dissimilar fashions. Although this description is overly simplistic and entire texts have been devoted to both types of relationship, in the physicianpatient relationship, the physician's job is to prevent,

Inadequate: Findings from a Tri-State Study, 47 GERONTOLOGIST 604, 604 (2007) (studying how guardianship statutes may be improved by increasing physician/clinical participation in guardianship proceedings).

21. Regarding qualitative social science research techniques in a context with relevance to the legal profession, see generally Joshua Perry, The Ethical Costs of Commercializing the Professions: First-Person Narratives from the Legal and Medical Trenches, 13 U. PA. J. L. \& Soc. Change 13 (2010).

22. The author thanks the physicians who spoke with him about this project. Because these physicians spoke with the expectation that their comments would only be reported anonymously, they are not acknowledged here by name. 
diagnose, discover, and, if possible, remedy an illness and alleviate suffering. The legal system is based on an adversarial process; the attorney has an ethical duty to fervently represent a client and attempt to win the case or argument, which is often decided by a third unaffected party: jury, judge, or mediator. Winning may not be synonymous with truth or justice. . . Even though an argument could be made that neither relationship ... is ideal or even just, it is telling that they are so different. ${ }^{23}$

Treating physicians normally are driven by, and organize the great bulk of their energies and activities around, a therapeutic model focused on the patient's medical welfare. ${ }^{24}$ Oriented thusly toward clinical consequences, treating physicians are generally tolerant of "bumbling through," even despite some legal ambiguity, and respect the patient's autonomy so long as medical harm to the patient does not result. ${ }^{25}$ Efficiency and flexibility in responding to the medical immediacy of the patient's needs is important to accomplish the physician's patient care function. ${ }^{26}$ In the course of treating the patient, the physician ordinarily is not looking for, let alone collecting and documenting, legally admissible evidence, since the patient's legal status rarely will matter in carrying out the physician's job to make the patient "better;" hence, the physician may appear recalcitrant to the attorney not because the physician is intentionally behaving difficultly, but rather just because the physician does not possess the data necessary to answer the question posed by the attorney regarding decision-making competence.

23. Richard D. Zane, The Legal Process, 27 Emergency Med. Clinics N. Am. 583, 583-84 (2009) (alteration in original) (citation omitted).

24. See, e.g., Neil Sharpe \& Ronald Carter, Genetic Testing: Care, Consent, AND LIABILITY 4-5 (2006) (providing a brief history of the therapeutic model of patient care).

25. Marshall B. Kapp, Decisional Capacity in Theory and Practice: Legal Process Versus 'Bumbling Through,' 6 AgING \& MENTal Health 413, 413 (2002) (discussing the points pro and con for initiating formal guardianship proceedings for persons whose decision-making competence has been called into question).

26. See American Healthways, Defining the Patient-Physician Relationship for the 21st Century, http://www.cardiophonics.com/PatientPhysician.pdf (last visited Nov. 11, 2010) (discussing the importance of flexibility in the patientphysician relationship). 
By contrast, the elder law attorney likely is influenced by a more forensic, or legal authority clarification oriented, paradigm. ${ }^{27}$ This model basically entails a process-orientated intent on obtaining absolute legal certainty regarding the rights and duties of all the respective parties to a medical, financial, or personal transaction. If necessary, that certainty will be achieved through the adversary system. Attorney bias in this direction is based heavily on elder law practitioners' experience working with a skewed sample in which legal bumbling through has not worked very well for vulnerable older clients and other parties with whom those clients have dealt. ${ }^{28}$

A second significant factor contributing to attorney-treating physician friction is physician apprehension that the physician's cooperation in a legal process (such as guardianship), which might have the ultimate effect of overriding or limiting the patient's stated wishes, would be interpreted by the patient as a moral betrayal. ${ }^{29}$ Physicians worry that such perceived betrayal, especially when it entails the sharing of otherwise confidential patient medical information with third parties, ${ }^{30}$ will engender a diminution of trust and thereby destroy or impair continuation of the beneficial physician-patient fiduciary relationship. ${ }^{31}$ Additionally, physicians are anxious that their cooperation in a legal process that diminishes the patient's autonomy may be antitherapeutic, hence offensive to the ethical principle of

27. Zane, supra note 23, at 584 (discussing the legal process and how attorneys generally evaluate cases).

28. The dichotomous differentiation of physicians as healers versus attorneys as adversaries, although generally accurate, is not inevitable and immutable. See Charity Scott, Doctors as Advocates, Lawyers as Healers, 29 Hamline J. Pub. L. \& POL'Y 331, 331 (2008).

29. See Desla Mancilla \& Sue Biedermann, Health Information Privacy: Why Trust Matters, 28 Health Care Manager 71, 71 (2009) (discussing the distrust in the technology that maintains and transmits consumers' health information); $c f$. Dan R. Reilly, Breaching Confidentiality and Destroying Trust: The Harm to Adolescents on Physicians' Rosters, 54 CAN. FAM. Physician 834, 834 (2008) (discussing the importance to teenagers of physician-patient confidentiality in the Canadian medical system).

30. Regarding statutory permission for the physician to share patient information in the competence context, see, for example, WIS. STAT. AnN. $\S$ 905.04(4) (a) (West Supp. 2009).

31. Regarding the historic trust or fiduciary nature of the physician-patient relationship, see, for example, JenNifER JaCKSON, TruTH, Trust \& MEdicine (2001) (discussing trust and honesty in physician-patient relationships); Mark A. Hall, Law, Medicine and Trust, 55 STAN. L. Rev. 463, 463 (2002) (discussing the nature and value of trust, and its relationship to the law). 
beneficence, ${ }^{32}$ by helping to bring about a legal outcome that (from the patient's own perspective) makes the patient's life worse than it was before. For instance, the physician's assistance to an attorney in establishing a guardianship for a person who has no family, but who vehemently wishes to remain in his or her own home, despite deficits in the Instrumental Activities of Daily Living (IADL), ${ }^{33}$ might result in the guardian compelling the resisting person to enter an undesired nursing home.

Another factor contributing to attorney-treating physician tension in this context is the fact that, in the modern, frequentlyfragmented, uncoordinated American health care non-system, the primary care physician often does not interact with a patient to a great extent during the patient's times of substantial challenge and stress. ${ }^{35} \quad$ During those most difficult situations, the patient's immediate care is often, at least temporarily, transferred to a medical specialist such as a hospitalist, ${ }^{36}$ intensivist, ${ }^{37}$ or nursing home Medical Director. ${ }^{38}$ Thus, the primary care physician ordinarily has little reason to question, let alone to document, the patient's behaviors decision-making competence or patient that conceivably could reflect on the patient's competence during office-based encounters that are conducted for routine purposes such as monitoring the patient's blood pressure and lipid and

32. See generally Edmund D. Pellegrino \& David C. Thomasma, For the Patient's Good: The Restoration of Beneficence in Health Care (1988) (discussing the principle of beneficence and the actual and supposed conflicts it has with patient autonomy and justice).

33. See generally M. Powell Lawton \& Elaine M. Brody, Assessment of Older People: Self-Maintaining and Instrumental Activities of Daily Living, 9 GERONTOLOGIST 179 (1969) (discussing one scale for measuring the human functioning of the elderly).

34. See Marshall B. Kapp, "A Place Like That": Advance Directives and Nursing Home Admissions, 4 Psychol. Pub. POL'y \& L. 805, 805 (1998) (discussing the resistance of many people to nursing home admission).

35. See Gulshan Sharma et al., Continuity of Outpatient and Inpatient Care by Primary Care Physicians for Hospitalized Older Adults, 301 J. AM. MED. Ass'N 1671, 1671 (2009) (discussing change over time in continuity of care in older hospitalized patients, and the transition from outpatient to inpatient care).

36. See Thomas E. Baudendistel \& Robert M. Wachter, The Evolution of the Hospitalist Movement in the USA, 2 CLINICAL MED. 327, 327 (2002) (discussing the move toward and the impact of the hospitalist system).

37. See Gulshan Sharma et al., Continuity of Care and Intensive Care Unit Use at the End of Life, 169 ARCHIVES INTERNAL MED. 81, 81 (2009) (discussing the outpatient-to-inpatient continuity of care over time for terminal lung cancer patients).

38. James E. Fanale, The Nursing Home Medical Director, 37 J. AM. GERIATRIC SOC'Y 369, 370 (1989). 
thyroid levels. ${ }^{39}$ So long as the patient appears to be reasonably compliant with medical instructions (for example, appearing on time for scheduled appointments independently or assisted by someone else, answering the physician's questions succinctly and affirmatively, and going along without complaint with laboratory tests and physical examinations), the primary care physician rarely generates and memorializes on an ongoing basis the sort of direct evidence regarding a patient's decision-making competence that an attorney would find useful in a legal proceeding. ${ }^{40}$ As stated by one pair of commentators:

In the ideal case, the medical record contains a detailed, quantitative assessment of cognitive function on the date at issue. Unfortunately, such records are rare. Almost as useful is the medical record that contains multiple quantitative assessments of cognitive function prior to and after the date in question. ... But records of this type are also rare. ${ }^{41}$

Physicians' inadequate professional education regarding the operation of the legal system generally, and particularly the lack of much or any systematized training to hone forensic diagnostic or documentary skills, ${ }^{42}$ are additional factors cited by physicians to help explain their reluctance to get involved with attorneys in cases raising competence questions about present or former patients. To the extent that medical schools and accredited medical residency programs have incorporated into their curricula any attention to the legal and ethical facets of informed patient consent for proposed medical interventions, it is likely that most of that instruction pertains to the informed element of the consent doctrine, $^{43}$ with particular emphasis on the tangible, written

39. Sharma et al., supra note 35 , at 1671 (discussing in general how lack of continuity between outpatient and inpatient care may lead to a decreased continuity of information).

40. Id.

41. Streisand \& Spar, supra note 16 , at 183.

42. See, e.g., Ryan C.W. Hall et al., Testamentary Capacity: History, Physicians' Role, Requirements, and Why Wills Are Challenged, 17 CLINICAL GERIATRICS 18, 18 (2009) ("Unfortunately, most doctors, even those who primarily see patients of advanced years, are not knowledgeable about key issues surrounding testamentary capacity.").

43. See generally Heather B. Sherman et al., Teaching Pediatric Residents How to Obtain Informed Consent, 80 ACAD. MED. S10, S10 (2005) ("The lack of formal instruction makes it difficult for [medical] residents to develop an accurate knowledge base about the components of informed consent."); Tsiao Y. Yap et al., A Physician-Directed Intervention: Teaching and Measuring Better Informed Consent, 84 
documentation of consent ${ }^{44}$ and other risk management considerations. ${ }^{45}$ Medical students and residents are-at best—only generally familiar with the element of informed consent that requires a competent decision maker and likely receive scant, if any, structured instruction dedicated specifically to improving their knowledge or clinical evaluation skills in the arena of capacity/competence to give medical informed consent. ${ }^{46}$ Even less attention is paid in most medical schools and post-graduate training programs to developing future medical practitioners' skills in assessing and documenting patients' decision-making competence for purposes besides obtaining informed consent to medical interventions.

ACAD. MED. 1036, 1037 (2009) (indicating that information overload by the parents of children needing innovative treatment for leukemia hampers the informed consent process). Regarding the informed element of the informed medical consent legal doctrine, see, for example, Jessica J. Flinn, Personalizing Informed Consent: The Challenge of Health Literacy, 2 ST. LOUIS U. J. HeAlTH L. \& POL'Y 379, 379 (2009) ("If informed consent is to properly represent a patient's knowledge and understanding of risks, then [the patient's] health literacy must be considered."); Steven G. Rado, A Patient's Right to Know: A Case for Mandating Disclosure of Physician Success Rate as an Element of Informed Consent, 18 Health MATRIX 501, 530 (2008) (arguing that specific legislation should be introduced to expand the informed consent doctrine to include physician success rates).

44. Regarding the importance of written documentation of informed medical consent, see, for example, Memorandum from Ctrs. for Medicare \& Medicaid Servs., Dep't. of Health \& Human Servs. to State Survey Agency Dirs. 9 (Apr. 13, 2007), available at http://www.cms.hhs.gov/SurveyCertificationGenInfo/downloads /SCLetter07-17.pdf (explaining revisions to Hospital Interpretive Guidelines for Informed Consent). The memorandum observes the importance of written documentation of informed medical consent:

The medical record must contain a document recording the patient's informed consent for those procedures and treatments that have been specified as requiring informed consent. Medical staff by-laws should address which procedures and treatments require written informed consent. There may also be applicable Federal or State law requiring informed consent. The informed consent form contained in the medical record should provide evidence that it was properly executed. Id.

45. See, e.g., Brendan G. Magauran, Risk Management for the Emergency Physician: Competency and Decision-Making Capacity, Informed Consent, and Refusal of Care Against Medical Advice, 27 Emerg. Med. Clin. N. Am. 605, 605 (2009) (discussing the important role informed consent plays in the risk management practices of emergency room physicians); David E. Thiess et al., Hot Topics in Risk Management in Neurologic Practice, 28 Neurol. Clin. 429, 429 (2010) (discussing ways in which physicians can meet the terms of the informed consent doctrine).

46. See, e.g., Karen L. McClean \& Sharon Card, Informed Consent Skills in Internal Medicine Residency: How Are Residents Taught, and What Do They Learn?, 79 ACAD. MED. 128, 128 (2004) ("No consistent approach to teaching or evaluating informed consent skills exists within Canadian [internal medicine] programs.”). 
A few limited exceptions to the foregoing general statements should be noted. A significant amount of instruction regarding both the theoretical and clinical assessment aspects of determining decision-making competence is woven into virtually all residency programs in the medical specialties of psychiatry and neurology, ${ }^{47}$ and additional attention is devoted to this matter in geriatric, forensic psychiatry, ${ }^{48}$ and geriatric psychiatry ${ }^{49}$ fellowship programs. Additionally, in the last decade a number of substantial grants awarded by the Donald W. Reynolds Foundation ${ }^{50}$ and the Association of American Medical Colleges (AAMC) ${ }^{51}$ to American

47. See Am. Bd. of Psychiatry and Neurology, Psychiatry and Neurology CORE COMPETENCIES Version 4.1, 8-12 (2004), available at http:// www.abpn.com/downloads/core_comp_outlines/core_psych_neuro_v4.1.pdf

("To communicate effectively and work collaboratively with other healthcare and other professionals involved in the lives of patients and families. . . in the community system, physicians shall ... demonstrate knowledge of the legal aspects of psychiatric and neurological diseases as they impact patients and their families.").

48. See Am. Bd. of Psychiatry and Neurology, Forensic Psychiatry Core Competencies Outline 2.1, 2-6 (2005), available at http:// www.abpn.com /downloads/core_comp_outlines/core_FP_2.1.pdf ("To conduct a forensic evaluation for non-treatment purposes of an individual and develop a wellreasoned forensic psychiatric opinion," forensic psychiatrists shall demonstrate knowledge of "[c]ivil issues, including . . . competency/guardianship/ conservatorship \& testamentary capacity" and shall demonstrate "[s]pecial consultations and investigations ... [with] attorneys" as well as the ability "[t]o communicate forensic data and opinions in written format through forensic reports and/or testimony.").

49. See Am. Bd. of Psychiatry and Neurology, Geriatric Psychiatry Core COMPETENCIES OUTLINE 2.1, 1-4 (2004), available at http://www.abpn.com /downloads/core_comp_outlines/core_GP_2.1.pdf ("Geriatric psychiatrists shall gather essential and accurate information through interviews with their geriatric psychiatric patients, family members, caregivers and other health professionals with attention to . . . [c]ompetency assessments (e.g., decisions regarding treatment, personal care, etc.). . . . Geriatric psychiatrists shall develop and apply specific knowledge for education in geriatric psychiatry, including . . . [p] ractice related ... policy and legal issues ... . [such as f] orensic issues."); see also Susan J. Lieff et al., Proposed Geriatric Psychiatry Core Competencies for Subspecialty Training, 13 AM. J. Geriatric Psychiatry 815, 815 (2005) (discussing "the theoretical and practical development of proposed core competencies for subspecialty training and certification in geriatric psychiatry").

50. Donald W. Reynolds Found., www.dwreynolds.org/programs/national /aging/aging.htm (last visited Sept. 8, 2010) (stating the foundation's goal is to improve "the quality of life for America's elderly by preparing physicians to provide better care for frail older people.").

51. Ass'n of Am. Med. Colls., http://www.aamc.org/newsroom/presskits /geriatrics.htm (last visited Sept. 8, 2010) ("Beginning in January 2000, the AAMC managed a $\$ 4.8$ million grant program for The John A. Hartford Foundation to aid medical schools in the advancement of geriatric and gerontology studies 
medical schools to enhance the level of geriatrics education for all of their students likely have had the effect of influencing the recipient schools to include more training regarding the clinical evaluation of decision-making capacity and competence in older patients. Despite these important but limited exceptions, however, most treating physicians (particularly primary care providers) are quite uncomfortable with their low degree of educational preparation for the role of evidence supplier in legal contexts involving the questioning of a patient's competence. ${ }^{52}$

Another serious source of attorney-physician tension in situations where the physician's assistance is sought in evaluating and proving a client/patient's decision-making competence is the set of anxieties that many physicians sense concerning their own exposure to legal liability for becoming involved in the competence determination process. $^{53}$ To a large extent, these physician-held legal anxieties are free-floating and not firmly anchored to any specific, concretely identifiable reason. Instead, fears derive from physicians' general distaste of attorneys, the adversarial system for resolving disagreements, and the process of cross examination in particular. Such fears are not exactly alleviated when attorneys, speaking for their profession, make such public assertions as: "Cross examination is about control. ... [T] he focus should not be on the witness, but on the attorney. The witness is nothing more than a trained monkey (a trained, talking monkey that is), confirming or denying the attorney statements. ${ }^{, 54}$ Stated a bit more diplomatically:

The attorney, while presenting evidence, also presents witnesses whose opinions favor their argument in the case. The system is, by definition, adversarial, and therefore both sides collect and organize evidence as it is best presented to further their arguments, including diametrically divergent options from [witnesses]....

Expert witnesses are often the focus of much scrutiny regarding their motivation and the lack of impartiality of their testimony. ${ }^{55}$

through integrative and innovative curricula.").

52. See ABA-APA, supra note 2, at 31-40.

53. See, e.g., Magauran, supra note 45, at 606-07.

54. Streisand \& Spar, supra note 16, at 193.

55. Zane, supra note 23, at 589 (alteration added) (citations omitted). 
Finally (although the list of factors enumerated here in no way pretends to be comprehensive), some physicians consider the time commitment and emotional hassles that their involvement with attorneys and the legal system generally entails to be an undesirable distraction from their important medical practices and the therapeutic patient benefit that those medical practices pursue. $^{56} \quad$ Practicing physicians overwhelmingly characterize themselves as being extremely busy and needing, in the words of one physician I interviewed, to "triage the paperwork to survive." 57 Making matters worse is the unavailability, in most situations, of meaningful financial reimbursement to physicians for the time expenditures and hassle encountered in cooperating with an attorney for the purpose of helping the attorney to definitively clarify the patient's legal status.

\section{ADDRESSING THE INTERPROFESSIONAL TENSION}

One possible reaction to the present state of affairs would be to maintain the status quo. Although the current level of interaction between elder law attorneys and treating physicians frequently is not ideal in the context of illuminating and clarifying an allegedly incompetent person's legal status and right to make particular kinds of legally significant decisions, both the medical and legal systems in the United States have somehow managed to bumble through for many years without unduly producing either anarchy or oppression. ${ }^{58}$ The medical-legal tensions identified in this article are very real, but it still may be best-all things considered-to leave well enough alone.

Despite the inertial predisposition against a serious disruption of the present situation, improvement could be achievable. First, if an insufficiency of physician knowledge and skills regarding the assessment of patients' decision-making competence is indeed a notable problem, then medical schools and postgraduate medical training programs could be incentivized and assisted to include more focused attention on instilling in their students and trainees a

56. See, e.g., $i d$. at 583; Changes in Decision-Making Capacity in Older Adults: AsSESSMENT AND InTERVENTION, supra note 15, at 121; Randye Retkin, Lawyers and Doctors Working Together: A Formidable Team, 20 No. 1 Health Law. 33, 33 (2007) (discussing the interprofessional antagonism that runs between doctors and attorneys).

57. Interview with psychiatrist, in Tallahassee, Fla. (Mar. 15, 2010).

58. Cf. Kapp, supra note 25, at 413-14. 
better knowledge base and skill set in this sphere. Such efforts might entail development of model curricula and teaching materials and the resolution of questions concerning who would implement the curricula, at what point in the student's or resident's educational career, and using which kinds of formats. Additionally, internal political questions within specific institutions would need to be addressed in order to carve out sufficient curricular time from already overloaded educational schedules and to allocate resources commensurately with the distribution of departmental responsibilities.

Even assuming arguendo that these kinds of programmatic details could be satisfactorily resolved, however, there are several reasons one might nonetheless doubt the efficacy of more formal medical education as a panacea for eliminating attorney-physician tension within the process of resolving the legal status of an allegedly incompetent person. To begin, when questions regarding an individual's decision-making capacity enter the legal arena (that is, once questions of capacity transform into issues of competence), particular court practices and procedures-as well as the practices and procedures of specific judges working within the same court system-vary enormously among ${ }^{59}$ and within ${ }^{60}$ different jurisdictions. No medical education curriculum could reasonably be expected to anticipate and prepare future physicians to respond precisely to such wide variations in judicial and administrative practice. Thus, generic medical education regarding attorneytreating physician interaction in the context of resolving a client's/patient's legal decision-making status has, even at its best, notable inherent limitations in its practical applicability. Moreover, imposing a mandate to include yet more curricular material in already overloaded training programs would (as noted above) potentially create additional political headaches for medical educators. Perhaps most importantly, one might well question the

59. The specific judicial division with authority to adjudicate issues pertaining to individuals' decision-making competence varies depending on the specific jurisdiction. Compare FLA. STAT. $\$ 744.102$ (2010) (placing the authority to hear and decide guardianship petitions in the state Circuit Court for each county), with 20 PA. CONS. STAT. $§ 5511$ (2005) (placing the authority to hear and decide guardianship petitions in the Orphans Court Division of the state Court of Common Pleas for each county).

60. Compare Carbon County O.C. R. 14.1, with Lycoming County O.C. R. L14.1, and ERIE COUNTY O.C. R. 14.1.1, and WestMoreland COUNTY O.C. R. W0501 (illustrating the differing guardianship adjudication procedures implemented by various counties within the single state of Pennsylvania). 
extent to which enhancement of training opportunities in this sphere will, by itself, be robust enough to overcome the several other powerful obstacles outlined earlier $^{61}$ to create a more productive attorney-treating physician interaction. Even if treating physicians possess better knowledge about how to be involved in this aspect of the legal process, how likely is it that they will want to be more involved?

If enhancement of medical, including postgraduate, education-however essential such enhancement may be-is not likely to be sufficient, and the other inhibiting factors cannot realistically be eliminated, how then can elder law attorneys in the future work to improve the quality of attorney-treating physician cooperation in the context of resolving decision-making competence issues? One fairly easily implementable suggestion is that elder law attorneys develop a straightforward written glossary of relevant legal terms, attentive to the idiosyncrasies of each attorney's own jurisdiction, to make available to the treating physicians from whom they solicit client-specific information. With the help of such a resource, all of the involved professionals would be working with a shared vocabulary and a lot of initial confusion and cross-purpose efforts could be curtailed. State and local bar association elder law committees could use groundbreaking work done by the American Bar Association and its partners as a starting point for producing such materials. ${ }^{62}$

Another recommendation would be for the attorney to frame information requests to the treating physician that focus on decision-specific abilities of the alleged incompetent person (namely: Does the person meet the competence criteria for autonomously making the specific decision at issue?), ${ }^{63}$ rather than querying the physician about the person's mental state in a global, open-ended sense. Inquiries crafted in terms of the precise areas of cognitive and emotional functioning ${ }^{64}$ necessary to decide the question actually, contemporaneously confronting the alleged

61. See supra notes 27-41, 59-60 and accompanying text.

62. See Am. Bar Ass'n \& Am. Psychological Ass'n, Assessment of Older Adults With Diminished CAPACITY: A handBoOK For Psychologists (2008).

63. See, e.g., Mathy D. Mezey et al., Advance Directives: Older Adults With Dementia, 16 Clinics Geriatric Med. 255, 256 (2000) (discussing decision-specific mental capacity).

64. Regarding the areas of cognitive and emotional functioning encompassed by the concept of decision-making competence, see for example, Karlawish, supra note 2 , at 93 . 
incompetent persons, geared to a specific set of circumstances and places, and accompanied by a clear explanation of why the competence inquiry is being posed at this time, are more likely to produce physician responses with meaningful evidentiary value. ${ }^{65}$

Additionally, elder law attorneys should resist the natural inclination to ask treating physicians, even within decision-specific frameworks, for a single, all-encompassing clinical-legal conclusion. Instead, treating physicians' responses to attorneys' requests for opinions about a patient's decision-specific, decision-making competence may be more worthwhile for the requesting attorney and the legal body resolving the matter when the attorney guides the physician to support conclusions with relatively brief answers to a series of questions that break the competence evaluation into its separate data components. Namely, the separate components are: the individual's ability to make and communicate any discernible choice; the individual's ability to comprehend his or her own specific situation; the person's ability to reason with the available information in reaching a decision; and the individual's ability to appreciate the probable and possible consequences of the alternatives being contemplated. ${ }^{66}$ Many physicians may be better able, and more willing, to deal with attorneys at that concrete level of analysis and explanation than they would be to offer broad, undifferentiated conclusions regarding a particular patient's decision-making competence.

A further potential avenue of positive interprofessional synergy might entail attempts by attorneys dealing with questions of an individual's mental competence to use treating physicians to help pursue clinical or therapeutic interventions, as opposed to legal or adversarial ones, on behalf of the person about whom decisionmaking competence questions have been expressed.

There are many situations that are not adversarial, in which the attorney, client, and family are all seeking to serve the client's interests and to maximize capacity and autonomy. One important result of a capacity assessment may be specific recommendations for clinical interventions that may be recommended by the lawyer and pursued by the client and family to improve or

65. ABA-APA, supra note 2, at 39.

66. See, e.g., Laura B. Dunn et al., Assessing Decisional Capacity for Clinical Research or Treatment: A Review of Instruments, 163 Aм. J. Psychiatry 1323, 1323 (2006) (noting the four components of decisional capacity). 
stabilize the client's functioning. For example, in the case of the older client who has become delusional in the context of a hearing impairment, isolation, and anxiety, clinical interventions to address all three (hearing aids, more social contact, anti-anxiety medication) may very well reduce or eliminate delusions and restore the individual's capacity. In other situations, more frequent oversight and assistance with nutrition and medication may increase the client's lucidity. ${ }^{67}$

If these collaborative efforts are successful, the need for a formal competence evaluation by the treating physician, an expert consultant, and the court may be obviated or, at the least, delayed. Fulfilling a therapeutic role on behalf of the individual patient is the natural historical fit for treating physicians, ${ }^{68}$ just as the costs and benefits of any contemplated intervention-that is, the net therapeutic impact-for each of the proper parties in a scenario should be a paramount consideration for the legal system and its cast of professional actors. ${ }^{69}$

\section{CONCLUSION}

Whatever else might accurately be predicted about the practice of elder law in the next part of the twenty-first century, it will be imperative for attorneys in this developing professional specialty to learn to work more collaboratively with medical practitioners in a panoply of contexts that hold ramifications for the health and legal well-being of older people who are both attorneys' clients and physicians' patients. One of those contexts involves situations in which an older person's cognitive and emotional ability to make specific kinds of important, legally consequential life choices truly autonomously ${ }^{70}$ has been called into

67. ABA-APA, supra note 2, at 40.

68. See John H. Warner, The therapeutic Perspective: Medical Practice, KNOWLEDGE, AND IDENTITY IN AMERICA 1820-1885, at 83-91 (1986) (examining the therapeutic perspective on orthodox medicine in America between the 1820s and 1880s).

69. See Marshall B. Kapp, A Therapeutic Approach, in TheOrIEs on LAw AND AgEING: The JuRISPRUdence OF Elder LAW 31, 31-32 (Israel Doron ed., 2009) (evaluating the therapeutic and anti-therapeutic effects of law and the legal process on older individuals).

70. The ethical principle of autonomy or self-determination lies at the core of the concept of valid adult decision making. See, e.g., Alasdair Maclean, Autonomy, Informed Consent and Medical LaW: A Relational Challenge 9-47 (2009) (analyzing the ethical basis for consent and the meaning and importance 
question by someone with the right to raise that issue. The process for addressing the decision-making competence question is an interprofessional, medical-legal matter. It is in everyone's best interests, and especially that of the alleged incompetent person, that the quality of interprofessional interaction in this arena be improved.

of autonomy). 